\title{
Association Between Thionamides and Acute Pancreatitis: A Case-Control Study
}

\author{
Jia-Yin Guo, ${ }^{1,2}$ Chia-Ling Chang, ${ }^{3,4}$ and Ching-Chu Chen ${ }^{2,5}$
}

Background: Thionamides have been extensively used to treat patients with hyperthyroidism worldwide. Recent pharmacovigilance studies have revealed a safety signal between carbimazole or methimazole and pancreatitis. The associated risk remains unclear.

Methods: We identified patients with newly diagnosed acute pancreatitis from 2000 to 2013 as the case group from the Taiwan Longitudinal Health Insurance Database 2000, which contains data from 1996 to 2013. Each patient with acute pancreatitis was matched for age, sex, comorbidities, and cancer with four controls through propensity score matching. A total of 52 patients without matched controls were excluded. Sensitivity analyses including the 52 excluded patients were performed using a matching ratio of 1:2. Odds ratios (ORs) along with 95\% confidence intervals (CIs) for the association were estimated using multivariate logistic regression.

Results: We included 9204 and 36,816 patients in the case and control groups, respectively. The proportions of patients who had used thionamides, carbimazole, methimazole, and propylthiouracil were similar in these two groups. In addition, the adjusted OR (CI) for the association of acute pancreatitis with thionamides was 1.03 (0.86-1.24), with carbimazole it was $0.90(0.63-1.30)$, with methimazole it was $1.05(0.84-1.31)$, and with propylthiouracil it was $1.00(0.74-1.34)$. The sensitivity analysis results were unchanged.

Conclusions: We were unable to demonstrate an association between acute pancreatitis and usage of thionamides.

Keywords: thionamides, carbimazole, methimazole, propylthiouracil, pancreatitis, hyperthyroidism

\section{Introduction}

T ThIONAMides HAVE BEen used to treat patients with hyperthyroidism for many years. On January 4, 2019, the Pharmacovigilance Risk Assessment Committee of the European Medicines Agency published a recommendation regarding the safety signals of carbimazole and methimazole (1). The committee recommended that carbimazole or methimazole should be discontinued immediately if patients develop acute pancreatitis during treatment, and that for patients with a history of acute pancreatitis, clinicians should avoid re-exposing patients to carbimazole or methimazole after a previous administration of one of these drugs. The Medicines and Health care Products Regulatory Agency of the United Kingdom followed these recommendations and published the same safety signal on February 18, 2019 (2). However, the associated risk remains clinically unclear.
The aim of this retrospective case-control study was to evaluate the associations of thionamides in general and carbimazole, methimazole, and propylthiouracil in particular with acute pancreatitis using Taiwan's Longitudinal Health Insurance Database 2000 (LHID2000). This study was approved by the Research Ethics Committee of China Medical University and Hospital (CMUH-104-REC2115-R3).

\section{Methods}

\section{Study population}

The LHID2000 contains all claims data for 1 million insured subjects from 1996 to 2013, who were randomly selected from Taiwan's National Health Insurance Research Database. International Classification of Diseases, Ninth Revision, Clinical Modification (ICD-9-CM) codes

\footnotetext{
${ }^{1}$ Department of Medicine, China Medical University, Taichung, Taiwan.

${ }^{2}$ Division of Endocrinology and Metabolism, Department of Medicine, China Medical University Hospital, Taichung, Taiwan.

${ }^{3}$ Management Office for Health Data, China Medical University Hospital, Taichung, Taiwan.

${ }^{4}$ School of Medicine, China Medical University, Taichung, Taiwan.

${ }^{5}$ Department of Medicine, School of Chinese Medicine, China Medical University, Taichung, Taiwan.
}

(C) Jia-Yin Guo et al., 2020; Published by Mary Ann Liebert, Inc. This Open Access article is distributed under the terms of the Creative Commons License (http://creativecommons.org/licenses/by/4.0), which permits unrestricted use, distribution, and reproduction in any medium, provided the original work is properly cited. 
are used to define disease diagnoses from outpatient and inpatient data in the LHID2000. The ICD-9-CM codes used in this study are presented in Supplementary Table S1.

We identified patients with new diagnoses of acute pancreatitis-defined as $\geq 2$ outpatient visit diagnoses or $\geq 1$ diagnosis during hospitalization or an emergency visitas the case group. The exclusion criteria included the following: index date not within the study period (2000-2013), age younger than 20 years, age older than 100 years, and missing sex or age data. The diagnosis date was defined as the index date. We used the same exclusion criteria to identify patients without a history of acute pancreatitis as the control group; these controls were matched for age, sex, comorbidities (including alcoholic liver disease, gallbladder stone, hyperlipidemia, and type 2 diabetes mellitus), and cancer with the case group through propensity score matching at a ratio of 1:4. A total of 52 patients without matched controls were excluded. Sensitivity analyses including the 52 excluded patients were performed at a matching ratio of $1: 2$ to clarify the effect of excluding the 52 unmatched patients on the association. The status of antithyroid drug use was categorized as never use and ever use.

\section{Statistical analyses}

Chi-square tests were used to compare categorical variables. Odds ratios (ORs) along with $95 \%$ confidence intervals (CIs) for the association were estimated using multivariate logistic regression. The ORs were adjusted for age, sex, alcoholic liver disease, gallbladder stone, and cancer. All statistical analyses were performed using STATA/SE version 14.0 (STATA Corp., College Station, TX). Results with a two-sided $p$-value of $<0.05$ were considered significant.

\section{Results}

As shown in Figure 1, from the total of 1 million patients in the LHID2000, 10,963 patients with newly diagnosed acute pancreatitis were included in the case group. We excluded 1536 patients for whom the date of diagnosis was not within the study period; 171 patients without sex or age data, aged $<20$ years, or aged $>100$ years; and 52 patients without matched controls (including 3 patients who had been prescribed thionamides). Finally, a total of 9204 patients were included in the case group. For the control group, we identified 989,037 patients without a history of acute pancreatitis. From these patients, 234,744 were excluded using the same

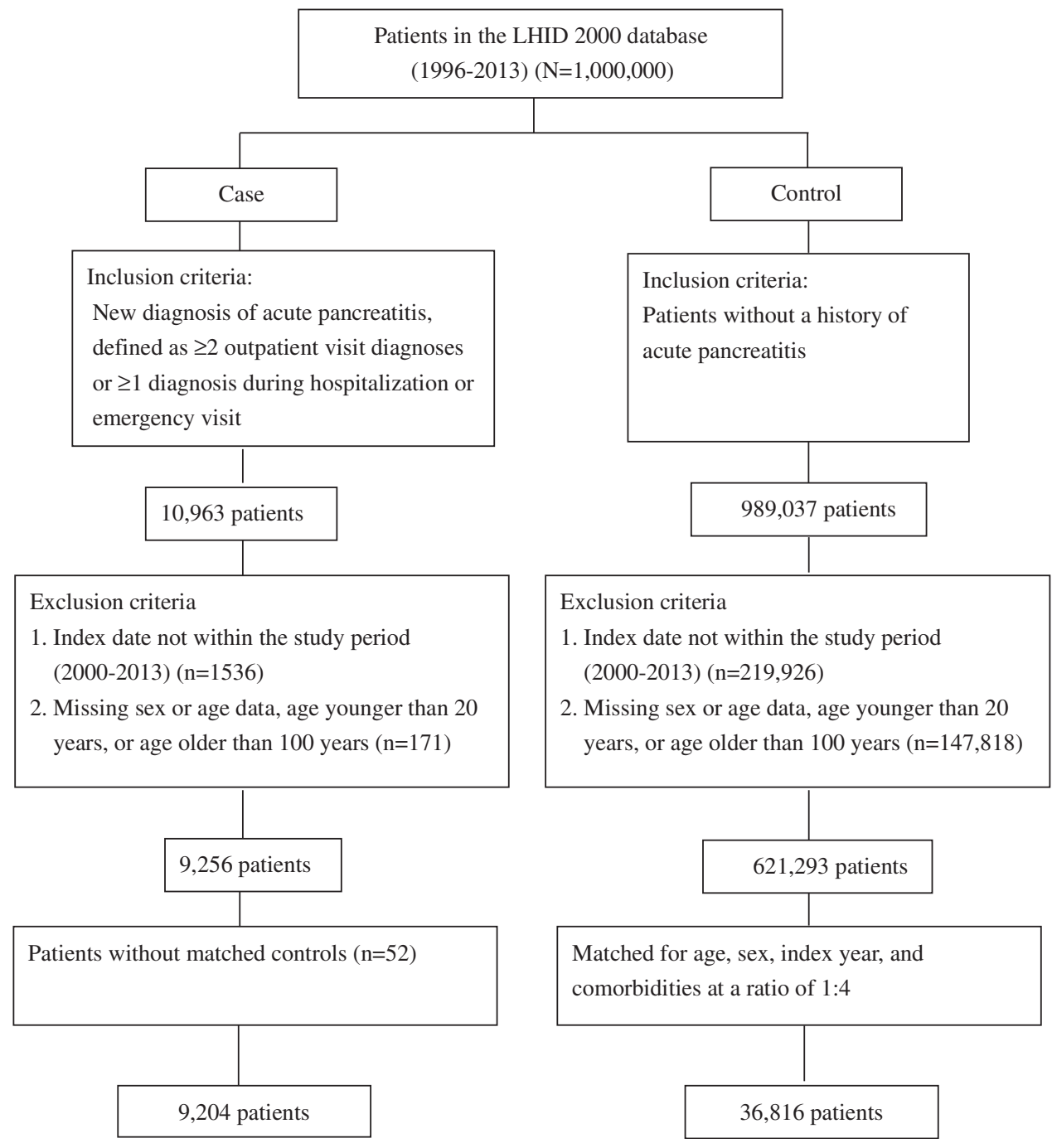

FIG. 1. Flowchart of included patients. LHID, Longitudinal Health Insurance Database. 
Table 1. Characteristics of Patients

\begin{tabular}{|c|c|c|c|}
\hline & \multicolumn{2}{|c|}{ Acute pancreatitis } & \multirow[b]{2}{*}{$\mathrm{p}$} \\
\hline & $\begin{array}{c}\text { Yes (case) } \\
(\mathrm{n}=9204) \\
\mathrm{n}(\%)\end{array}$ & $\begin{array}{c}\text { No (control) } \\
(\mathrm{n}=36,816) \\
\mathrm{n}(\%)\end{array}$ & \\
\hline \multicolumn{3}{|l|}{ Thionamides } & 0.970 \\
\hline Never & $9058(98.41)$ & $36,234(98.42)$ & \\
\hline Ever & $146(1.59)$ & $582(1.58)$ & \\
\hline \multicolumn{3}{|l|}{ Carbimazole } & 0.539 \\
\hline Never & $9168(99.61)$ & $36,655(99.56)$ & \\
\hline Ever & $36(0.39)$ & $161(0.44)$ & \\
\hline \multicolumn{3}{|l|}{ Methimazole } & 0.822 \\
\hline Never & $9103(98.90)$ & $36,422(98.93)$ & \\
\hline Ever & $101(1.10)$ & $394(1.07)$ & \\
\hline \multicolumn{3}{|l|}{ Propylthiouracil } & 0.976 \\
\hline Never & $9148(99.39)$ & 36,591 (99.39) & \\
\hline Ever & $56(0.61)$ & $225(0.61)$ & \\
\hline \multicolumn{3}{|l|}{ Sex } & 0.744 \\
\hline Women & $3516(38.20)$ & $14,132(38.39)$ & \\
\hline Men & $5688(61.80)$ & $22,684(61.61)$ & \\
\hline \multicolumn{3}{|l|}{ Age } & $<0.001$ \\
\hline$<40$ & $2382(25.88)$ & $7639(20.75)$ & \\
\hline $40-65$ & $4066(44.18)$ & $16,999(46.17)$ & \\
\hline$\geq 65$ & $2756(29.94)$ & $12,178(33.08)$ & \\
\hline \multicolumn{4}{|l|}{ Comorbidity } \\
\hline \multicolumn{3}{|c|}{ Alcoholic liver disease } & $<0.001$ \\
\hline Without & $8198(89.07)$ & $33,612(91.30)$ & \\
\hline With & $1006(10.93)$ & $3204(8.70)$ & \\
\hline \multicolumn{3}{|c|}{ Gallbladder stone } & $<0.001$ \\
\hline Without & $6768(73.53)$ & $26,252(71.31)$ & \\
\hline With & $2436(26.47)$ & $10,564(28.69)$ & \\
\hline \multicolumn{3}{|l|}{ Hyperlipidemia } & 0.904 \\
\hline Without & $6288(68.32)$ & $25,128(68.25)$ & \\
\hline With & $2916(31.68)$ & $11,688(31.75)$ & \\
\hline \multicolumn{3}{|l|}{ Type 2 diabetes } & 0.256 \\
\hline Without & $6878(74.73)$ & $27,723(75.30)$ & \\
\hline With & $2326(25.27)$ & $9093(24.70)$ & \\
\hline \multicolumn{3}{|l|}{ Cancer } & $<0.001$ \\
\hline Without & $8671(94.21)$ & $34,310(93.19)$ & \\
\hline With & $533(5.79)$ & $2506(6.81)$ & \\
\hline
\end{tabular}

exclusion criteria as the case group. Finally, the control group comprised 36,816 patients who were matched with the case group for age, sex, index year, and comorbidities at a ratio of $1: 4$.

As presented in Table 1, the proportions of patients who had ever used thionamides ( $1.59 \%$ vs. $1.58 \%)$, carbimazole $(0.39 \%$ vs. $0.44 \%)$, methimazole $(1.10 \%$ vs. $1.07 \%)$, and propylthiouracil $(0.61 \%$ vs. $0.61 \%)$ were similar in the case and control groups. Patients with acute pancreatitis were younger than those without acute pancreatitis. The proportion of patients with alcoholic liver disease was higher in the case group than in the control group; however, the proportions of patients with gallbladder stone and cancer were lower in the case group than in the control group.

As indicated in Table 2, the adjusted OR (CI) for acute pancreatitis was $1.03(0.86-1.24)$ for thionamides, 0.90 (0.63-1.30) for carbimazole, $1.05(0.84-1.31)$ for methima- zole, and 1.00 (0.74-1.34) for propylthiouracil. Sensitivity analyses conducted using a matching ratio of 1:2 (9256 patients vs. 18,512 patients; Supplementary Table S2) revealed that the risks of acute pancreatitis remained unchanged in users of all thionamides (1.10 [CI: 0.90-1.35]), carbimazole users (1.00 [CI: 0.67-1.49]), methimazole users (1.08 [CI: 0.85-1.37]), and propylthiouracil users (1.16 [CI: 0.83-1.61]; Supplementary Table S3).

\section{Discussion}

This study demonstrates no significant association between usage of thionamides (methimazole, carbimazole, and propylthiouracil) and the development of acute pancreatitis. However, previous studies have reported that acute pancreatitis was associated with methimazole or carbimazole use in nine patients (3-11). Propylthiouracil is the only thionamide without a case report, suggesting an association with the development of acute pancreatitis. As presented in Table 3, the onset of acute pancreatitis symptoms after methimazole or carbimazole exposure varied from 4 to 90 days. All symptoms and laboratory abnormalities resolved after the drug were withdrawn. The recurrent rate of acute pancreatitis after thionamide withdrawal was unknown. However, acute pancreatitis recurred in five of the five patients (four methimazole users and one carbimazole user) who were rechallenged with the original thionamide $(3,4,8-10)$. The interval between rechallenge and the recurrence of acute pancreatitis ranged from 3 hours to 5 days. However, none of the authors mentioned whether these five patients ever experienced acute pancreatitis previously, before ever being exposed to thionamides, or ultimately developed chronic pancreatitis (Supplementary Table S4). Some case reports did not exclude viral infections $(8,10)$ or autoimmune disease $(3,8,10)$ as a potential etiology of acute pancreatitis. Potassium iodide (one patient), propylthiouracil (two patients), and radioactive iodine (four patients) were administrated for the management of hyperthyroidism after acute pancreatitis resolved.

The results of the present study are consistent with those of a previous study that reported no association between methimazole and the development of acute pancreatitis (12). Moreover, an animal study revealed that methimazole reduced the severity of cerulean-induced acute pancreatitis in rats (13). An additional study reported that propylthiouracil attenuated pancreatic activity to reduce the mortality rate of hemorrhagic pancreatitis in dogs (14).

The strengths of this study include its large real-world sample, which compensates for the absence of a randomizedcontrolled study. Nevertheless, despite this strength, some limitations should be acknowledged. First, the exclusion of 52 unmatched patients may have compromised the results; however, sensitivity analyses reinforced the findings. Second, a causal relationship cannot be determined using insurance claims data. Third, although the case and control groups were matched for age, sex, and some comorbidities, potentially important confounders may have been unavailable for adjustment.

In conclusion, we were unable to demonstrate an association between the development of acute pancreatitis and use of thionamides. 
Table 2. Association Between Antithyroid Drugs and Acute Pancreatitis

\begin{tabular}{|c|c|c|c|c|c|c|c|c|}
\hline & \multicolumn{2}{|c|}{ Thionamides } & \multicolumn{2}{|c|}{ Carbimazole } & \multicolumn{2}{|c|}{ Methimazole } & \multicolumn{2}{|c|}{ Propylthiouracil } \\
\hline & $\begin{array}{c}\text { Adjusted } \\
\text { OR }(C I)\end{array}$ & $\mathrm{p}$ & $\begin{array}{c}\text { Adjusted } \\
\text { OR (CI) }\end{array}$ & $\mathrm{p}$ & $\begin{array}{c}\text { Adjusted } \\
\text { OR (CI) }\end{array}$ & $\mathrm{p}$ & $\begin{array}{c}\text { Adjusted } \\
\text { OR }(C I)\end{array}$ & $\mathrm{p}$ \\
\hline \multicolumn{9}{|l|}{ Drug } \\
\hline Never & Ref. & & Ref. & & Ref. & & Ref. & \\
\hline Ever & $1.03(0.86-1.24)$ & 0.751 & $0.90(0.63-1.30)$ & 0.581 & $1.05(0.84-1.31)$ & 0.655 & $1.00(0.74-1.34)$ & 0.994 \\
\hline \multicolumn{9}{|l|}{ Sex } \\
\hline Women & Ref. & & Ref. & & Ref. & & Ref. & \\
\hline Men & $0.96(0.91-1.01)$ & 0.098 & $0.96(0.91-1.01)$ & 0.089 & $0.96(0.91-1.01)$ & 0.097 & $0.96(0.91-1.01)$ & 0.094 \\
\hline \multicolumn{9}{|l|}{ Age (years) } \\
\hline$<40$ & Ref. & & Ref. & & Ref. & & Ref. & \\
\hline $40-65$ & $0.76(0.72-0.81)$ & $<0.001$ & $0.76(0.72-0.81)$ & $<0.001$ & $0.76(0.72-0.81)$ & $<0.001$ & $0.76(0.72-0.81)$ & $<0.001$ \\
\hline$\geq 65$ & $0.75(0.70-0.80)$ & $<0.001$ & $0.75(0.70-0.80)$ & $<0.001$ & $0.75(0.70-0.80)$ & $<0.001$ & $0.75(0.70-0.80)$ & $<0.001$ \\
\hline \multicolumn{9}{|l|}{ Comorbidity } \\
\hline \multicolumn{9}{|c|}{ Alcoholic liver disease } \\
\hline Without & Ref. & & Ref. & & Ref. & & Ref. & \\
\hline With & $1.31(1.21-1.41)$ & $<0.001$ & $1.31(1.21-1.41)$ & $<0.001$ & $1.31(1.21-1.41)$ & $<0.001$ & $1.31(1.21-1.41)$ & $<0.001$ \\
\hline \multicolumn{9}{|c|}{ Gallbladder stone } \\
\hline Without & Ref. & & Ref. & & Ref. & & Ref. & \\
\hline With & $0.96(0.91-1.02)$ & 0.195 & $0.97(0.91-1.02)$ & 0.198 & $0.96(0.91-1.02)$ & 0.195 & $0.96(0.91-1.02)$ & 0.197 \\
\hline \multicolumn{9}{|l|}{ Cancer } \\
\hline Without & Ref. & & Ref. & & Ref. & & Ref. & \\
\hline With & $0.89(0.81-0.99)$ & 0.026 & $0.89(0.81-0.99)$ & 0.026 & $0.89(0.81-0.99)$ & 0.026 & $0.89(0.81-0.99)$ & 0.026 \\
\hline
\end{tabular}

Adjusted for age, sex, alcoholic liver disease, gallbladder stone, and cancer.

CI, 95\% confidence interval; OR, odds ratio.

Table 3. Case Reports of Methimazole- or Carbimazole-Induced Acute Pancreatitis

\begin{tabular}{|c|c|c|c|c|c|c|c|c|c|}
\hline Authors & $\begin{array}{l}\text { Reporting } \\
\text { year }\end{array}$ & Ethnicity & Age & Sex & Diagnosis & $\begin{array}{c}\text { Time of } \\
\text { symptom onset }\end{array}$ & Drug & $\begin{array}{l}\text { Dose } \\
(m g)\end{array}$ & Management \\
\hline $\begin{array}{l}\text { Taguchi } \\
\text { et al. (3) }\end{array}$ & 1999 & Japanese & 66 & $\mathrm{~W}$ & Graves' disease & $\begin{array}{l}21 \text { days } \\
3 \text { hours after } \\
2 \text { nd dose }\end{array}$ & MMI & $\begin{array}{l}30 \\
10^{\mathrm{a}}\end{array}$ & PTU \\
\hline $\begin{array}{l}\text { Marazuela } \\
\text { et al. (4) }\end{array}$ & 2002 & Spanish & 33 & W & Graves' disease & $\begin{array}{l}30 \text { days } \\
1 \text { day }\end{array}$ & Carbimazole & $\begin{array}{l}45 \\
10^{\mathrm{a}}\end{array}$ & RAI \\
\hline Su et al. (5) & 2008 & Chinese & 19 & $\mathrm{~W}$ & Graves' disease & 75 days & MMI & 10 & RAI \\
\hline $\begin{array}{l}\text { Chng } \\
\text { et al. (6) }\end{array}$ & 2011 & Asian & 70 & W & Graves' disease & 14 days & Carbimazole & 30 & RAI \\
\hline $\begin{array}{l}\text { Abraham } \\
\text { et al. (7) }\end{array}$ & 2012 & Caucasian & 80 & W & Unspecified & 90 days & MMI & 10 & Unspecified \\
\hline Yang et al. (8) & 2012 & Chinese & 18 & $\mathrm{~W}$ & Graves' disease & $\begin{array}{l}4 \text { days } \\
\text { Within } 1 \text { day }\end{array}$ & MMI & $\begin{array}{l}20 \\
10^{\mathrm{b}} \\
10^{\mathrm{b}} \\
10^{\mathrm{b}}\end{array}$ & PTU \\
\hline Jung et al. (9) & 2014 & Korean & 51 & M & Graves' disease & 14 days 5 hours & MMI & $\begin{array}{l}20 \\
10^{\mathrm{a}}\end{array}$ & Unspecified \\
\hline $\begin{array}{l}\text { Agito } \\
\quad \text { et al. (10) }\end{array}$ & 2015 & Caucasian & 51 & W & Toxic MNG & $\begin{array}{l}21 \text { days } \\
5 \text { days }\end{array}$ & MMI & $\begin{array}{l}10 \\
10^{\mathrm{a}}\end{array}$ & RAI \\
\hline $\begin{array}{l}\text { Kikuchi } \\
\quad \text { et al. (11) }\end{array}$ & 2018 & Japanese & 76 & W & Graves' disease & 19 days & MMI & 10 & $\begin{array}{l}\text { Potassium } \\
\text { iodide }\end{array}$ \\
\hline
\end{tabular}

There is no report of recurrent rate of acute pancreatitis in patients who were not re-exposed to thionamides.

${ }^{a}$ Rechallenged.

${ }^{\mathrm{b}}$ Rechallenged three times at different times by three physicians.

M, men; MMI, methimazole; MNG, multinodular goiter; PTU, propylthiouracil; RAI, radioactive iodine; W, women. 


\section{Authors' Contributions}

C.C.C., J.Y.G., and C.L.C. designed the study and analyzed and interpreted the data. C.C.C., J.Y.G., and C.L.C. drafted the article, and C.C.C. critically revised the article. C.C.C. approved the article, is the guarantor of this work, and takes responsibility for the integrity of the data and the accuracy of the analyses.

\section{Author Disclosure Statement}

No competing financial interests exist.

\section{Funding Information}

This work was supported by grants from the Ministry of Health and Welfare, Taiwan (MOHW108-TDU-B-212133004), China Medical University Hospital, Academia Sinica Stroke Biosignature Project (BM10701010021), MOST Clinical Trial Consortium for Stroke (MOST 107-2321-B039-004-), Tseng-Lien Lin Foundation, Taichung, Taiwan, and Katsuzo and Kiyo Aoshima Memorial Funds, Japan.

\section{Supplementary Material}

Supplementary Table S1

Supplementary Table S2

Supplementary Table S3

Supplementary Table S4

\section{References}

1. European Medicines Agency, Pharmacovigilance Risk Assessment Committee (PRAC). PRAC recommendations on signals, adopted at the 26-29 November 2018 PRAC meeting. Available at https://www.ema.europa.eu/en/documents/pracrecommendation/prac-recommendations-signals-adopted-2629-november-2018-prac-meeting_en.pdf (accessed July 15, 2019).

2. Medicines and Healthcare Products Regulatory Agency 2019 Carbimazole: risk of acute pancreatitis. Drug Safety Update, vol. 12, issue 7. Available at https://www.gov.uk/ drug-safety-update/carbimazole-risk-of-acute-pancreatitis (accessed August 5, 2019).

3. Taguchi M, Yokota M, Koyano H, Endo Y, Ozawa Y 1999 Acute pancreatitis and parotitis induced by methimazole in a patient with Graves' disease. Clin Endocrinol 51:667-670.
4. Marazuela M, Sánchez de Paco G, Jiménez I, Carraro R, Fernández-Herrera J, Pajares JM, Gómez-Pan A 2002 Acute pancreatitis, hepatic cholestasis, and erythema nodosum induced by carbimazole treatment for Graves' disease. Endocr J 49:315-318.

5. Su DW, Zou DJ 2008 One case of methimazole-induced acute pancreatitis. Chinese J Pract Med 24:2915.

6. Chng CL, Kek PC, Khoo DH 2011 Carbimazole-induced acute pancreatitis and cholestatic hepatitis. Endocr Pract 17:960-961.

7. Abraham A, Raghavan P, Patel R, Rajan D, Singh J, Mustacchia P 2012 Acute pancreatitis induced by methimazole therapy. Case Rep Gastroenterol 6:223-231.

8. Yang M, Qu H, Deng HC 2012 Acute pancreatitis induced by methimazole in a patient with Graves' disease. Thyroid 22:94-96.

9. Jung JH, Hahm JR, Jung J, Kim SK, Kim S, Kim KY, Kim BR, Kim HJ, Jeong YY, Kim SJ 2014 Acute pancreatitis induced by methimazole treatment in a 51-year-old Korean man: a case report. J Korean Med Sci 29:1170-1173.

10. Agito K, Manni A 2015 Acute pancreatitis Induced by methimazole in a patient with subclinical hyperthyroidism. J Investig Med High Impact Case Rep 3:2324709615592229.

11. Kikuchi I, Miyata N, Yoshimura Y, Miyamoto K, Tachikawa N 2019 Methimazole-induced acute pancreatitis: a case report. Clin J Gastroenterol 12:239-242.

12. Lai SW, Lin CL, Liao KF 2016 Use of methimazole and risk of acute pancreatitis: a case-control study in Taiwan. Indian J Pharmacol 8:192-195.

13. Yönetçi N, Oruç N, Ozütemiz AO, Kumanlioglu K, Yüce G, Batur Y 2002 Effects of methimazole pretreatment on cerulein induced acute pancreatitis in rats. Exp Toxicol Pathol 54:197-201.

14. Thompson BW, Lipin RJ, Clark RL 1964 Propylthiouracil in acute hemorrhagic pancreatitis. Arch Surg 88:966967.

Address correspondence to: Ching-Chu Chen, MD

Division of Endocrinology and Metabolism Department of Medicine China Medical University Hospital 2, Yude Road Taichung 40447 Taiwan

E-mail: chingchu@ms15.hinet.net 